\title{
Analysis of the Impact of Information Standardization on the Improve- ment of Market Efficiency
}

\author{
Zhihui Feng ${ }^{1,2}$, Feiqi Deng, ${ }^{1, *}$ Yuhui Zhang ${ }^{2}$, Xuan Luo $^{2}$ and Wei Wang ${ }^{2}$ \\ ${ }^{1}$ College of Automation Science and Engineering, South China University of Technology, Guangzhou, 510641, China; \\ ${ }^{2}$ Guangzhou Institute of Standardization, Guangzhou, 510502, China
}

\begin{abstract}
Based on the case of China's timber market, the paper analyses the impact of information standardization on the improvement of market efficiency. Information standardization can week the extent of asymmetric information, reduce the information costs in trade, and hence enlarge the market scale. Our microeconomic model shows that, if there is uncertainty in the market demand and market supply, the trader's loss due to the unbalance of the market will be reduced as the market scale increasing. Therefore, information standardization will benefit the traders from scale economy.
\end{abstract}

Keywords: Information standardization, market scale, trade efficiency.

\section{INTRODUCTION}

Standardization of products is an important means to improve the production and transaction efficiency. In the industry, the diversity of products can be reduced in production section through standardization. However, timber is a natural product. The characteristics such as variety, quality and shape are largely different, and this diversity character is unable reduced in production section, which seriously affects the transaction efficiency in timber market. How can we enhance the timber market efficiency by standardization method? The standardization of timber market is mainly implemented in circulation section, and the standardization of product information is an important section of it. This paper will analyze this problem through the micro economic method.

There are mainly four styles of standardization. (1) Compatible and interactive standard. This kind of standard mainly set the specification and quality of products to increase the matching chance in production and usage. (2) Minimum quality and safety standards. This is one of the manage method, to make sure the product and service quality meets the minimum requirement of relevant department. (3) Diversity reduction standard. Decreasing the diversity of products is to increase the number of each species, in order to have an effect on scale economic. (4) Information standard. This kind of standard is mainly about the identification and certification, providing information for consumers, which will benefit the market competition. To solve the information asymmetric problem, the government should regulate the logo contents and then supervise the enterprises.

The main bottleneck of Chinese timber market is the information standardization problem. In the present Chinese timber market, the information of species, material, size, volume and etc. are different in the inspection methods and standards [1-8]. For example, in the scale transfer method of $\log$, the promotion unit of Chinese national timber standard is $2 \mathrm{~cm}$, when the size is less than $2 \mathrm{~cm}$, carry a digit when it is not less than $1 \mathrm{~cm}$ and ignore when it is less than $1 \mathrm{~cm} \mathrm{[9].}$ For example, $9.0-9.9 \mathrm{~cm}$ is considered as $10 \mathrm{~cm}$. However, in some areas of south China, the carry method of timber size calculation is using following methods in production or transaction sections. (1) Double diameter calculation: the figure carries a digit when it is $2 \mathrm{~cm}$. For example, $9.0-9.9 \mathrm{~cm}$ is the same with $8 \mathrm{~cm}$ in this calculation method. (2) Single double diameter calculation: use the double diameter and single diameter calculation: Ignore the decimals behind the integer. For example, $9.0-9.9 \mathrm{~cm}$ will be regarded as $9 \mathrm{~cm}$, and $8.0-8.9 \mathrm{~cm}$ will be regarded as $8 \mathrm{~cm}$. (3) double diameter abdication calculations: Use the previous level when the figure is less than $1.5 \mathrm{~cm}$. Otherwise, use the next level. For example, $9.5-9.9 \mathrm{~cm}$ will be calculated as $10 \mathrm{~cm}$ and $9.0-9.4$ $\mathrm{cm}$ will be calculated as $8 \mathrm{~cm}$. These differences in calculation lead to the difference in volume, price and tax of timber [10-12].

In the timber market, since the information standards are not consistent, so every side of transaction must pay great costs in information searching and verifications. Otherwise, for two deals happened in different markets, due to the difficulty of timber quality and quantity comparison, it is too hard to know which market is cheaper even the price is certain. Therefore, the markets in different regions are difficult to play a role in mutual adjustment. In some extent, the markets are mutual independent and difficult to merge into a unified market. In addition, people are prefer a transaction way in real life rather than online. The transaction mode in internet seems has a poor outlook.

If the information of product can be standardized, and these standards will be implemented strictly, all the sides in the transaction are able to obtain the quality or specification information of timber from standardized information. Therefore it can save all kinds of information costs and improve 
the transaction efficiency. In fact, the benefits from information standardization are not only save costs. This is only the direct benefit, while there are some significantly indirect benefits. For example, information standardization can expand the timber transaction from local area to national market, or even international market, from traditional physical market to internet market. All sides of transaction can share the benefits from the expansion of market scale. However, this problem has not been discussed in theories.

Some authors have researched the influence from standardization to market efficiency. Among these most of the articles are descriptive or preliminary analyses on text. Seldom of them has use the micro economic model to analyze. For example, $\mathrm{Yu}$ from the concept of standardization, clear the connotation and function of agricultural standardization, and use the micro economic demand and supply model to compare the change of welfare of the traders before and after the standardization [8]. Thus, she has worked out the influence of the agricultural standardization in reducing transaction costs in agricultural products market, regulating market orders, and promoting market competition.

Due to the limit of the model, Yu's article can only reflect the direct benefits of information standardization. Previous analysis has pointed out that the standardization also has significant indirect benefits. For example, information standardization can make the original separated market merge into a large one. All the sides of the transaction can share the profits from expansion market scale.

In the second chapter, we will build a micro model to analyze the economic benefits from expansion market scale. Assuming the supply and demands from all the sides of the market are uncertain, so that the market is in a state of imbalance of supply and demand. The profits of the traders will be affected from the market imbalance. From this model, the more the traders in the market, the less the trader's' expect loss will be obtained from the imbalance of market supply and demand. One application of this conclusion is that the information standardization expand the market scale, and increase the expect profits of all the sides of the market.

The third chapter summarizes the basic conclusion of this paper, and puts forward relevant policy suggestions.

\section{TRANSACTION EFFICIENCY MODEL}

Assuming there are $N$ independent market. To simplify the model, we can assume that every market is homogeneous, which means they have the same market mechanism and structure. Assuming there are $m_{d}$ demanders and $m_{s}$ producers, and the number of total demand commodity for No. $i$ market is $x_{i}$, and the number of total supply commodity is $y_{i}$. Meanwhile $x_{i}$ and $y_{i}$ are two independent same distributed nonnegative integer random variables, and $i=1,2,3 \ldots \mathrm{N}$. To simplify it, assume the equilibrium price of production is exogenous, which will not be influenced by transaction. Assuming every producer can earn a profit of $\pi_{s}$. Every demander buys a product and put it into production as an essential factor, can earn a profit of $\pi_{d}$.

In a situation that there is no standardization in the market, every market is mutual independent. Since the quantity of supply and demand of market $i$ is $x_{i}$ and $y_{i}$, the number of successful transaction commodity is $\min \left\{x_{i}, y_{i}\right\}$. Since there are $m_{d}$ demanders in the market, so the average profit of every demander is

$$
E\left\{\pi_{d}(1)\right\}=\frac{\pi_{d}}{m_{d}} \operatorname{Emin}\left\{x_{i}, y_{i}\right\}
$$

In the same way, there are $m_{s}$ producers in ther market and the average profit of every producer is

$$
E\left\{\pi_{s}(1)\right\}=\frac{\pi_{s}}{m_{s}} \operatorname{Emin}\left\{x_{i}, y_{i}\right\}
$$

Among these equations, 1 stands for the only 1 independent market in this market.

If all products in the $N$ markets are forced to use the same information standards, and merge the original independent market into an unified one. Then the quantity of demand is $\Sigma x_{i}$, and the quantity of supply is $\Sigma x_{i}$. the number of successful transaction commodity is $\min \left\{\Sigma x_{i}, \Sigma y_{i}\right\}$. Since there are $m_{d} N$ demanders in the market, so the average profit of every demander is

$E\left\{\pi_{d}(N)\right\}=\frac{\pi_{d}}{m_{d} N} \mathrm{E} \min \left\{\sum_{i=1}^{N} x_{i}, \sum_{i=1}^{N} y_{i}\right\}$

In the same way, there are $m_{s} N$ producer, and the average profit of every producer is

$E\left\{\pi_{s}(N)\right\}=\frac{\pi_{s}}{m_{s} N} \mathrm{E} \min \left\{\sum_{i=1}^{N} x_{i}, \sum_{i=1}^{N} y_{i}\right\}$

Among these equations, $N$ stands for $N$ independent markets in this market.

Lemma 1: For arbitrary $x_{i}$ and $y_{i}, i=1,2,3 \ldots n$,

$\min \left\{\sum_{i=1}^{n} x_{i}, \sum_{i=1}^{\mathrm{n}} y_{i}\right\} \geq \sum_{i=1}^{n} \min \left\{x_{i}, y_{i}\right\}$

Proof: We might set

$\sum_{i=1}^{n} x_{i} \geq \sum_{i=1}^{n} y_{i}$

Then, we can get

$$
\begin{aligned}
& \min \left\{\sum_{i=1}^{n} x_{i}, \sum_{i=1}^{n} y_{i}\right\}=\sum_{i=1}^{n} y_{i} \\
& \text { Because } y_{i} \geq \min \left\{x_{i}, y_{i}\right\}, \text { then } \\
& \sum_{i=1}^{n} y_{i} \geq \sum_{i=1}^{n} \min \left\{x_{i}, y_{i}\right\}
\end{aligned}
$$

Formula 2.5 is proved.

Lemma 2:

$\frac{1}{n} \mathrm{E} \min \left\{\sum_{i=1}^{n} x_{i}, \sum_{i=1}^{n} y_{i}\right\}$ is monotone increasing to $\mathrm{n}$.

Proof: 
$\frac{1}{n} \mathrm{E} \min \left\{\sum_{i=1}^{n} x_{i}, \sum_{i=1}^{n} y_{i}\right\}=\frac{1}{n(n-1)} \mathrm{E} \min \left\{(n-1) \sum_{i=1}^{n} x_{i},(n-1) \sum_{i=1}^{n} y_{i}\right\}$

$=\frac{1}{n(n-1)} \operatorname{Emin}\left\{\sum_{j=1}^{\mathrm{n}} \sum_{i=1 \mathrm{C} 0 i \neq j}^{n} x_{i}, \sum_{j=1}^{n} \sum_{i=1}^{n} y_{i}\right\}$

From Lemma 1,

$$
\begin{aligned}
& \frac{1}{n(n-1)} \operatorname{Emin}\left\{\sum_{j=1}^{\mathrm{n}} \sum_{i=1 \mathrm{C} 0 i \neq j}^{n} x_{i}, \sum_{j=1}^{n} \sum_{i=1}^{n} y_{i}\right\} \\
& \geq \frac{1}{n(n-1)} \sum_{j=1}^{n} \operatorname{Emin}\left\{\sum_{\mathrm{i}=1 \mathrm{C} 0 \mathrm{i} \neq \mathrm{j}}^{\mathrm{n}} \mathrm{x}_{\mathrm{i}}, \sum_{i=1}^{n} y_{i \neq j}\right\}
\end{aligned}
$$

Since $x_{i}$ is independent and identically distributed, and $y_{i}$ is independent and identically distributed, for arbitrary $1 \leq \mathrm{j} \leq \mathrm{n}$, we can get

$$
\operatorname{Emin}\left\{\sum_{\mathrm{i}=1 \mathrm{C} 0 \mathrm{i} \neq \mathrm{j}}^{\mathrm{n}} \mathrm{x}_{\mathrm{i}}, \sum_{i=1}^{n} y_{i \neq j}\right\}=\operatorname{Emin}\left\{\sum_{i=1}^{n-1} x_{i}, \sum_{i=1}^{n-1} y_{i}\right\}
$$

So

$\frac{1}{n(n-1)} \sum_{j=1}^{n} \operatorname{Emin}\left\{\sum_{\mathrm{i}=1 \mathrm{C} 0 \mathrm{i} \neq \mathrm{j}}^{\mathrm{n}} \mathrm{x}_{\mathrm{i}}, \sum_{i=1}^{n} y_{i \neq j}\right\}=\frac{1}{n-1} \operatorname{Emin}\left\{\sum_{i=1}^{n-1} x_{i}, \sum_{i=1}^{n-1} y_{i}\right\}$

Next, we will analyze the influence of market scale to market transaction efficiency. In an independent market, due to the mismatching between supply and demand, it leads to a low efficiency transaction. However in a large market, which is merged by $N$ market, the mismatching of supply and demand be can mutual mitigate in a way, and make the traders in the market obtain profits. The more the scale (represent as $N$ ) of the market is, the bigger the effect of the mitigating, and the more profits of the traders will be. Proposition 1 would prove this conclusion.

Proposition 1: In a large market merged by $N$ market, the average profit of producers and demanders will increase with the market scale.

Proof: From Lemma 2,

$$
\begin{aligned}
& E\left\{\pi_{d}(N)\right\}=\frac{\pi_{d}}{m_{d} N} \mathrm{E} \min \left\{\sum_{i=1}^{N} x_{i}, \sum_{i=1}^{N} y_{i}\right\} \\
& \geq \frac{\pi_{d}}{m_{d}(N-1)} E \min \left\{\sum_{i=1}^{N-1} x_{i}, \sum_{i=1}^{N-1} y_{i}\right\}=E\left\{\pi_{d}(N-1)\right\}
\end{aligned}
$$

In the same way,

$$
\begin{aligned}
& E\left\{\pi_{s}(N)\right\}=\frac{\pi_{s}}{m_{s} N} \mathrm{E} \min \left\{\sum_{i=1}^{N} x_{i}, \sum_{i=1}^{N} y_{i}\right\} \\
& \geq \frac{\pi_{s}}{m_{s}(N-1)} E \min \left\{\sum_{i=1}^{N-1} x_{i}, \sum_{i=1}^{N-1} y_{i}\right\}=E\left\{\pi_{s}(N-1)\right\}
\end{aligned}
$$

From Proposition 1, the merged market scale is always larger than an independent one, traders will gain more profits from merged one to an independent one.

Inference 1: In a large market which is merged from $\mathrm{N}$ markets, the average profits of the producers and demanders will always be more than in an independent market.
What benefits will information standardization bring to the traders? First, if the product information can be standardized, all the sides of the transaction can know the quality and specification of the timber, then save the information costs and increase transaction efficiency.

Second, information standardization provide a method to compare different products. In the same market, we can classify the products according to the quality, and compile the transaction price to market price index, so as to make a comparison with other market. For example, Guangdong Yuzhu international timber market is now the largest timber and wood wholesale market in China. "Yuzhu China's timber price index" has become the first Chinese national price index in Sep. 2012 [7].

Third, information standardization can help people compare the price between different markets. For the same product, people can buy in the cheaper market. The market with higher price has to reduce the price to compete with the other market. This process makes the prices in different markets gradually become the same. It is a process to make the different market merge into one. Therefore, the information standardization promote the merge of the markets. From Inference 1, we know that the market integration helps all the sides of transaction share the economic profits from the market scale.

Forth, the scope of the network market has cover the whole grid. In this sense, the network market is a trade method trough network to achieve market expansion. Compared with physical market, network market is more widespread, therefore, traders can share more profits (Proposition 1). However in network market, buyers cannot see the real commodities. They need the standardization information to help them search and verify commodities. Therefore, information standardization is the precondition to improve network market efficiency.

\section{CONCLUSION}

This paper takes China's timber market as an example, and use micro economic method to analyze the influence of product information standardization to market transaction efficiency. Product market standardization can not only reduce the information searching and verification cost to all sides of the market, but also strength the communication between different markets, and merge these independent markets into a large one.

The expansion of market has bring several benefits to all sides of the transaction. The model in this paper has analyzed one main situation. Assuming there is an imbalance in the supply and demand of all sides of the market, the profit of the traders will be affected by this imbalance. From this model, we can see the more the traders in the market, the less expect loss, which is due to the imbalance, will be. One application of this conclusion is the information standardization expands the scale of the market and increase the expect profit to all sides of the market.

In the process of market information standardization, it will influence the interests of some business, who utilize the original chaotic market information and seed for their own interests. Although information standardization can bring 
benefits to the whole timber market, but if there are some businessman refusing, it will be difficult to success. This requires the government to strictly enforce the standardization policy.

\section{CONFLICT OF INTEREST}

The authors confirm that this article content has no conflict of interest.

\section{ACKNOWLEDGEMENTS}

Declared none.

\section{REFERENCES}

[1] K.Chen, "Technical standardization problems in timber circulation field inspection and supervision," Agricultural resource management, vol. 4, pp. 17-20 2005.

[2] S. Gao, and Y. Yang, "Economical and social benefits analysis of standardization," Public Standardization, vol. 3, pp. 58-59, 2006.
[3] S. Guo, and Y. Nie, "Restricting factors and the reduce of Chinese timber circulation efficiency - based on supply chain theory," $J i$ nagsu business theory, vol. 10, pp. 15-17, 2008 .

[4] S. He, "Research to the influence of carry method of log ruler to timber size and volume," Forestry resource management, vol. 3 , pp. 12-14, 2002.

[5] C. Jiang, "Discussion on the economic and social benefits of standardization," Technical economic and management, vol. 10, 2014.

[6] J. Liu, "Discussion on the significance of timber standardization," Knowledge of Economic, vol. 18, no. 99, 2011.

[7] S. Niu, "Guangzhou: Yuzhu timber price has become the benchmark of Chinese timber market price," Nanfang Daily, vol. 27, 2012.

[8] G. Tu, "Investigation of the application of timber inspection technique in timber transportation," vol. 1, pp. 64-68, 2014.

[9] D.X, "The influence of unstandardized ruler to timber tax and price," Forestry economic problem, vol. 3, pp. 273-279, 2006.

[10] D.X, "The influence of unstandardized ruler to timber volume," Anhui Xuetong paper, vol. 5, pp. 96-97, 2007.

[11] L.Yu, "Analysis of the government promotion on the implementation of agricultural standardization," Agricultural economic problem, vol. 9, pp. 29-34, 2007.

[12] L. Yu, "Agricultural standardization and agricultural product quality level," China Agricultural economic, vol. 7, pp. 4-10, 2004.

Received: May 26, 2015

(C) Feng et al.; Licensee Bentham Open.

This is an open access article licensed under the terms of the (https://creativecommons.org/licenses/by/4.0/legalcode), which permits unrestricted, noncommercial use, distribution and reproduction in any medium, provided the work is properly cited. 